\title{
Small intestinal herniation through the broad ligament in a mare outside of the gestation period - a case report
}

\author{
Cristian Crecan ${ }^{1}$, Iancu Morar ${ }^{2}$, Mircea V. Mircean $^{3}$, Daniela Oros ${ }^{4}$, \\ Alexandra Muresan ${ }^{3}$, Marian Taulescu ${ }^{5}$
}

\begin{abstract}
University of Agricultural Sciences and Veterinary Medicine, Faculty of Veterinary Medicine, ${ }^{1}$ Anaesthesiology and Surgery Department, ${ }^{2}$ Department of Reproduction, Obstetrics and Veterinary Gynaecology, ${ }^{3}$ Department of Internal Medicine, ${ }^{4}$ Department of Animal Hygiene and Welfare, ${ }^{5}$ Pathology Department, Cluj-Napoca, Romania
\end{abstract}

Received March 19, 2018

Accepted December 7, 2018

\begin{abstract}
A Furioso-North Star mare, aged 8 years, was examined for colic signs. The mare had a history of dystocia and post partum vaginal lacerations, acute endometritis and laminitis approximately one year before the admission for colic. Signs of persistent abdominal pain, moderate distended abdomen, non-passage of manure, fever, tachycardia, tachypnoea, congested mucus membranes, and "toxic line" were recorded. No intestinal borborygmi were present in the four quarters of the abdomen. On rectal examination, the colon, the ventral band of the caecum, the right ovary and the uterine horn were palpated on the right side of the abdomen. The spleen, the nephrosplenic ligament, the left ovary and a firm, distended and painful small intestine (SI) loop were palpated on the left side. The left uterine horn and the adjacent broad ligament were not detectable. Percutaneous abdominal ultrasound evaluation revealed a large amount of fluid in the abdominal cavity, SI distention and absence of peristalsis. Abdominocentesis yielded approximately $20 \mathrm{ml}$ of red-tinged peritoneal fluid with increased mean protein concentration $(5.2 \mathrm{mg} / \mathrm{dl})$, white blood cell count $(12,550$ cells $/ \mu \mathrm{l})$, and lactate $(14 \mathrm{mmol} / \mathrm{dl})$. A presumptive diagnosis of SI strangulation was made. Surgical resection of the affected intestinal loops was recommended. Due to poor prognosis and financial limitations, the mare was euthanized. Post mortem macroscopic diagnosis was a herniation of 3 metres of the mid-jejunum through the left mesometrium, resulting in a complete and complicated strangulation. To prevent this type of SI strangulation, we recommend transrectal palpation of the urogenital tract (including the broad ligament) after foaling. If a defect is identified, we recommend flank laparoscopy for correction.
\end{abstract}

Colic, small intestine herniation, mesometrium, nonpregnant mare

Horses are susceptible to colic due to digestive tract particularities (Datt and Usenik 1975). Small intestinal strangulating obstructions (SISO) are encountered in 19-32\% of cases (van den Boom and van der Velden 2001). Strangulated obstructions of small intestine (SI) loops are the result of luminal blockage and concurrent compromise of the blood supply, followed by intestinal ischaemia, gangrene and/or rupture of the affected intestinal loops (Withers and Mair 2008).

The most frequent causes of SISO include pedunculated lipomas, epiploic foramen entrapment, incarceration in inguinal/scrotal hernia, volvulus, incarceration in mesenteric rent, incarceration by fibrous band/adhesions, intussusception, incarceration in the gastrosplenic ligament, diaphragmatic hernia and incarceration in the umbilical hernia or omental hernia (Withers and Mair 2008). In mares, SISO have also been associated with pregnancy, when the jejunum is entrapped over the broad ligament of the uterus (Santschi 2009). The broad ligament is a peritoneal fold, subdivided into the mesosalpinx, mesovarium and mesometrium, which attaches the oviduct, ovary, and uterine horns/body, respectively, to the abdominal and pelvic walls (Ginther 1992). During pregnancy, a rent in the broad 
ligament can be created by the kicking motions of the foal or by the foal repositioning for parturition in the last month of gestation (Ginther 1998).

Up to date, there have been only 4 cases of jejunal herniation through a rent in the broad ligament reported in the literature. The first was briefly mentioned in a study without stating the pregnancy status of the mare (Tennant et al. 1975). Two cases were reported in pregnant mares, one of which was described as a SI herniation through the mesometrium at 8 month of gestation (Becht and McIlwraith 1980), whereas the other was only briefly mentioned in a study by Freeman and Schaeffer (2011). The forth case was a SI herniation through the mesometrium in a nonpregnant mare with a history of 2 normal pregnancies (Steward et al. 2018). Given the rarity of this lesion, this case report describes in detail the clinical signs and pathological outcomes in a nonpregnant mare with SI herniation through the broad ligament, providing novel insights in diagnosis, possible treatment options and prevention.

\section{Case history}

\section{Case description}

In March 2015, a Furioso-North Star mare aged 8 years and weighing $700 \mathrm{~kg}$ was referred to the Equine Clinic of the Veterinary Medicine Faculty, Cluj-Napoca, Romania, for sudden onset of severe colic signs of 10 hours' duration. The mare had a history of dystocia caused by an oversized foetus and followed by severe post partum vaginal lacerations, acute endometritis and laminitis approximately one year before the current admission. The uterine involution was followed by a transrectal ultrasound examination performed twice at a 9-day interval. When the involution was complete, the left uterine horn remained bigger in size compared to the contralateral horn, which was of normal size. The full recovery period, including vaginal lacerations and laminitis, lasted around four months. The mare was not bred again.

\section{Clinical findings}

On admission, the mare showed signs of persistent abdominal pain, anxiety, sweating on the lateral sides of the neck and thorax, repeated pawing, and moderate abdominal distension; no faeces had been passed for $10 \mathrm{~h}$. The rectal temperature was $39.2^{\circ} \mathrm{C}$, the heart rate was 70 beats per min, and the respiratory rate 38 breaths per min. Mucous membranes were congested, capillary refill time was $6 \mathrm{~s}$, and a "toxic line" appeared above the incisive teeth. Skin fold testing was markedly delayed (4 s). Auscultation revealed no intestinal borborygmi in all abdominal quadrants. On percussion, local pain and a small region of gas distension were recorded in the dorsal part of the left flank. Nasogastric intubation yielded a spontaneous reflux of approximately 101 of fluid with $\mathrm{pH} 8$. On rectal examination, the colon and ventral band of the caecum with moderate distension and sensitivity, as well as the right ovary and uterine horn with normal aspects were palpated on the right caudal quadrant of the abdomen. A dense spleen without sensitivity, nephrosplenic ligament, a firm, distended and painful loop of SI, and the left ovary were palpated on the left caudal quadrant of the abdomen. The left uterine horn and the adjacent broad ligament were not detectable. No faeces were present in the rectum. Percutaneous abdominal ultrasonography revealed a large amount of fluid in the abdominal cavity, distension of SI loops and absence of peristalsis in all intestine segments. Abdominocentesis yielded approximately $20 \mathrm{ml}$ of red-tinged peritoneal fluid (PF), with a mean protein concentration of $5.2 \mathrm{mg} / \mathrm{dl}$, white blood cell count (WBC) 12,550 cells $/ \mu \mathrm{l}$, and lactate $14 \mathrm{mmol} / \mathrm{dl}$. The assessment of blood haematological and biochemical indices revealed lymphopaenia and granulocytosis, increased mean corpuscular haemoglobin concentration (MCHC) and decreased platelet count (Table 1), increased levels of aspartate aminotransferase (AST), alkaline phosphatase (ALP), blood urea nitrogen (BUN), cholesterol, triglycerides, total serum proteins (TP) 
Table 1. Haematological and biochemical outcomes.

\begin{tabular}{|c|c|c|}
\hline Category (unit) & Recorded values & Reference range** \\
\hline \multicolumn{3}{|l|}{ A. Haematology } \\
\hline $\mathrm{WBC}\left(10^{9} / \mathrm{L}\right)$ & 10.49 & $6.00-12.00$ \\
\hline LYM $\left(10^{9} / \mathrm{L}\right)$ & $1.37-$ & $1.50-5.50$ \\
\hline Lym* $\left(10^{9} / \mathrm{L}\right)$ & $28-$ & $30-40$ \\
\hline GRA $\left(10^{9} / \mathrm{L}\right)$ & $9.05+$ & $3.00-6.00$ \\
\hline Neutrophils* $\left(10^{9} / \mathrm{L}\right)$ & $6.4+$ & $5.0-6.0$ \\
\hline Eosinophils* $\left(10^{9} / \mathrm{L}\right)$ & 2 & $2-5$ \\
\hline $\operatorname{MON}^{*}\left(10^{9} / \mathrm{L}\right)$ & 6 & $5-6$ \\
\hline LYM (\%) & $13.1-$ & $25.00-60.00$ \\
\hline GRA $(\%)^{*}$ & $86.3+$ & $30.0-75.0$ \\
\hline $\mathrm{RBC}\left(10^{9} / \mathrm{L}\right)$ & 9.15 & $6.00-12.00$ \\
\hline HGB (g/dL) & 15.7 & $10.0-18.0$ \\
\hline $\operatorname{HCT}(\%)$ & 40.77 & $32.00-48.00$ \\
\hline $\operatorname{MCV}(\mu)$ & 45 & $34-58$ \\
\hline $\mathrm{MCH}(\mathrm{pg})$ & 17.1 & $13.0-19.0$ \\
\hline $\mathrm{MCHC}(\mathrm{g} / \mathrm{dL})$ & $38.5+$ & $13.0-37.0$ \\
\hline $\operatorname{PLT}\left(10^{9} / \mathrm{L}\right)$ & $56-$ & $100-600$ \\
\hline \multicolumn{3}{|l|}{ B. Biochemistry } \\
\hline$\overline{\mathrm{AST}}(\mathrm{U} / \mathrm{L})$ & $333.2+$ & $112.7-287.0$ \\
\hline $\operatorname{ALT}(\mathrm{U} / \mathrm{L})$ & 3.1 & $2.7-20.5$ \\
\hline GGT (U/L) & 13.2 & $2.7-22.4$ \\
\hline Creatinine (mg/dL) & 1.10 & $0.9-2.0$ \\
\hline BUN (mg/dL) & $32.1+$ & $10.4-24.7$ \\
\hline Glucose (mg/dL) & $200+$ & $62.2-114.0$ \\
\hline Cholesterol (mg/dL) & $177.3+$ & $70.9-141.9$ \\
\hline Triglycerides (mg/dL) & $193.7+$ & $11-59$ \\
\hline Total Protein $(\mathrm{g} / \mathrm{L})$ & $8.87+$ & $5.7-7.9$ \\
\hline Albumin (g/dL) & $4+$ & $2.5-3.8$ \\
\hline Calcium (mg/dL) & 13.3 & $10.4-13.4$ \\
\hline Phosphorus (mg/dL) & 2.4 & $2.3-5.4$ \\
\hline
\end{tabular}

*by manual cytology; **reference values of our laboratory; WBC, white blood cells; LYM, lymphocytes; GRA, granulocytes; MON, monocytes; RBC, red blood cells; HGB, haemoglobin; $\mathrm{HCT}$, haematocrit; $\mathrm{MCV}$, mean corpuscular; $\mathrm{MCH}$, mean corpuscular haemoglobin; MCHC, mean corpuscular haemoglobin concentration; PLT, platelet; AST, aspartate aminotransferase; ALT, alanine aminotransferase; GGT, gamma-glutamyl transferase; BUN, blood urea nitrogen; -, lower values compared to reference range; + , higher values compared to reference range. and albumin. The other biochemical indices were within the reference ranges (Table 1).

\section{Treatment}

The mare was unresponsive to the administered treatment: one dose of flunixin meglumine $1.1 \mathrm{mg} / \mathrm{kg}$ (Finadyne $^{\circledR}$ $50 \mathrm{mg} / \mathrm{ml}$, MSD Animal Health), two administrations of detomidine $0.05 \mathrm{mg} /$ $\mathrm{kg}$ (Domosedan ${ }^{\circledR} 10 \mathrm{mg} / \mathrm{ml}$ Pfizer Animal Health) and butorphanol $0.05 \mathrm{mg} / \mathrm{kg}$ (Butomidor $^{\circledR} 10 \mathrm{mg} / \mathrm{ml}$, Richter Pharma AG) over $1 \mathrm{~h}$. Between detomidine and butorphanol administrations, xylazine $1 \mathrm{mg} / \mathrm{kg}$ (Xylazin $\mathrm{Bio}^{\circledR} 2 \%$ Bioveta) was given at a 25 -min interval.

\section{Outcome}

A presumptive diagnosis of SISO was made, but it was not possible to identify the location of the intra-abdominal intestinal entrapment. Surgical resection of the affected SI loops was recommended, but due to poor prognosis and financial limitations, the owner chose euthanasia. After the informed consent, the mare was euthanized according to the ethical procedures and all applicable laws and regulations.

\section{Post mortem findings}

Post mortem examination was carried out within $2 \mathrm{~h}$ after euthanasia. Approximately 101 of serohaemorrhagic fluid were drained from the abdominal cavity. In the caudal third of the abdominal cavity, 8 $\mathrm{m}$ of distended jejunum were noticed, of dark red to black colour, with thickened walls and evidence of congestion and infarction (Plate III, Fig. 1). The adjacent mesentery was also thickened, oedematous, dark red with congested blood vessels. The affected jejunum contained ingesta, as well as haemorrhagic fluid. By manipulating the turgid jejunal mass, an internal incarceration of further $3 \mathrm{~m}$ of jejunum was identified. It had travelled through a rent in the left mesometrium. There was a secondary complete jejunal obstruction with a sharply defined line of demarcation between the strangulated and the non-affected intestinal segment (Plate III, Figs 2A, 2B). The intestinal segment proximal to the strangulation was also distended and had thickened walls, a large quantity of fluid in the lumen and haemorrhages on the serosa surface. The stomach was distended and had congested walls. The broad ligament was thickened, oedematous, with petechial haemorrhages and ecchymoses (Fig. 2B). Macroscopic examination of the genital apparatus 
revealed an oval rent in the left mesometrium. The portion of the ligament adjacent to the rent was thickened, and the edges of the rent were dense and grey-red in color, consistent with fibrosis (Plate IV, Fig. 3).

\section{Discussion}

Gastrointestinal colic in horses may vary from mild spasmodic to a life-threatening colic that can result in necrosis of the intestines, where surgery is needed (van der Linden et al. 2003). The degree of severity in SISO depends on the obstruction site, the time and degree of strangulation (Datt and Usenik 1975). Based on the strangulation site, one of the most rarely reported cause is SI herniation through the broad ligament (Steward et al. 2018). This pathology can occur in pregnant mares during late gestation, when the foal reaches a size that could influence the uterus position and SI migration into a created defect (Steward et al. 2018). Two cases have been reported in pregnant mares (Becht and McIlwraith 1980; Freeman and Schaeffer 2011). Recently, this pathology was reported in a nonpregnant mare with two past pregnancies without a history of dystocia (Steward et al. 2018).

In this case, a SI herniation through the mesometrium in a nonpregnant mare with a previous history of dystocia and severe post partum complications one year before the admission for colic was diagnosed. The mare showed severe signs of colic, moderately distended abdomen, persistent abdominal pain, no intestinal sounds in all abdominal quadrants, and non-passage of manure. Tachycardia, tachypnoea, congested mucous membranes, prolonged capillary refill time, and "toxic line" were recorded. Similar signs (except for congested mucous membrane) were reported in the previous case report described in the nonpregnant mare (Stew ard et al. 2018). These clinical signs are common in SISO (Withers and Mair 2008) and a definitive diagnosis can be made after additional diagnostic tests.

Rectal palpation revealed the right uterine horn in the right side of the abdominal cavity and distended SI loops in the left side of the abdominal cavity, with thickened walls and increased sensitivity to palpation. The increased mural thickness can occur due to a lack in the arterial or venous mesenterial supply followed by ischaemia, development of mural oedema or haemorrhage (Rowe and White 2008). Distention of the SI and a large amount of fluid was observed via transabdominal ultrasonography, similar to the case reported by Steward et al. (2018). The amount of gastric reflux was $\times 5$ higher than normal (2 1), most likely due to the complete obstruction and accumulation of the intestinal content proximal to the obstruction site (Mair and Edwards 2003). However, the increased volume of gastric reflux is not specific for SI obstructions (Withers and Mair 2008). The PF obtained by abdominocentesis was red-tinged in colour and had a high lactate concentration $(14 \mathrm{mmol} / \mathrm{l})$, similar to the case reported by Steward et al. (2018), in which the fluid was serosanguinous with a lactate concentration of $12.6 \mathrm{mmol} / \mathrm{l}$. Compared to a previous study in which horses with SISO had PT of $8.45 \mathrm{mmol} / \mathrm{dl}$ by Latson et al. (2005), in horses with SI through mesometrium, the PF lactate concentration seems to be up to almost $\times 2$ higher. A previous study has shown that large amounts of free $\mathrm{PF}$, as observed in our case, are statistically associated with a definitive diagnosis of SISO (Beccati et al. 2011). The increased free PF occurs because of vascular congestion, which leads to increased endothelial permeability and red blood cell diapedesis (Mair and Edwards 2003). The PF changes from colourless or light-yellow to red-tinged (Bach and Ricketts 1974). If ischaemia occurs in the intestinal wall, an exudative process develops and high amounts of protein and WBC move into the peritoneal cavity (Mair and Edwards 2003). The PF WBC and protein values recorded were higher than the normal values in adult horses (Hanson and Albanese 2015). Haematological and biochemical findings were also valuable indicators of SISO. Lymphopaenia may be explained by high 
circulating endogenous corticosteroid hormones secreted during stress (Welles 2000). Granulocytosis with neutrophilia may also be a stress indicator, secondary to increased cortisol concentration in horses with strangulating obstruction (Ayala et al. 2012; Weiss and Evanson 2003). The elevated MCHC suggests haemoconcentration, most likely associated with hypovolaemia, and it was also associated with higher mortality in horses undergoing surgery for a colic (Stephen et al. 2004). The haematocrit value was within the reference range. However, this indicator is not a sensitive marker of circulatory status in horses with enterocolitis, due to a splenic contraction and individual variation (Feary and Hassel 2006). We also recorded a low platelet count. This is one of the variables indicating the presence of disseminated intravascular coagulation (Monreal et al. 2000). It has been shown that consumptive coagulopathy is a frequent finding in horses with ischaemic strangulating and inflammatory gastrointestinal disorders, mostly observed in non-survivor cases (Monreal et al. 2000).

The elevated TP levels, albumin levels, and BUN could be due to dehydration (S to ckham 1995). In horses with SISO, the TP levels rise can also be related to the ongoing fluid and electrolyte losses that lead to haemoconcentration. However, in case of protein loss into the peritoneal cavity, TP may not be a reliable marker of the actual dehydration degree (Taylor 2002). The increased cholesterol and triglycerides were caused by anorexia or food restriction, which leads to fat mobilization; it can also be caused by the stress of pain as shown in colic horses (Gomaa et al. 2009). Hyperglycaemia is associated with transportation, stress, pain and acute or severe colic. Moreover, hyperglycaemia has been reported in the initial phase of endotoxaemia, and is associated with poor prognosis in horses with a colic (Hassel et al. 2009; Latson et al. 2005). The AST level was comparable with the one reported by Davis et al. (2003) in horses with SISO (337 $\pm 240 \mathrm{U} / 1)$.

Post mortem evaluation confirmed the SISO diagnosis and revealed a complete, complicated, closed loop jejunal herniation through the left mesometrium and irreversible intestinal necrosis. The vascular supply to herniated SI loops was damaged. The macroscopic lesions were segmental ischaemic necrosis of the incarcerated SI loops and distended stomach and intestinal segment proximal to the strangulation with haemorrhagic fluid inside. In horses with SISO, first the venous blood supply is compromised. Later, also the arterial mesenteric blood supply fails and the haemorrhage and congestion are turned into ischaemia. The SI proximal to the strangulation will dilate and progressively also become ischaemic (Hanson and Albanese 2015), as did the mare's SI and stomach in this case. Majority of macroscopic findings were similar to those previously reported in a nonpregnant mare with SI strangulation through mesometrium (Steward et al. 2018). Interestingly, the rent location and position along the left uterine horn was similar, including their length $(5 \mathrm{~cm})$ in the case report of Steward et al. (2018). The width was smaller in our case report ( $3 \mathrm{~cm}$ vs. $5 \mathrm{~cm}$ ) compared the case report of Steward et al. (2018). In contrast to the previous case report, in which the hernia occurred approximately one year after normal foaling (Steward et al. 2018), in our case it appears that the hernial ring was acquired during parturition. This assumption is based on the dystocia history one year before current admission and on the fibrotic edges of the rent.

A presumptive diagnosis of SI herniation through the broad ligament in a living mare can be made if specific signs of SI strangulation are associated with transrectal palpation, in which the urogenital tract can be only partially palpated. To confirm the diagnosis, flank laparoscopy can be a valuable tool for urogenital and intestinal tract evaluation, although the latter is challenging in adult horses (Hendrickson 2012). When performing the laparoscopy, it should be considered that even if the SI is easier to manipulate than the large intestine, in case of significant intestinal distention, there is a high risk for intestinal trauma (Hendrickson 2012). If SI strangulated loops have minor macroscopic changes without dilation, oedema and haemorrhages, standing surgery by flank laparoscopy is recommended 
(Hendrickson 2012) for correction of strangulation, followed by intracorporeal closure of the rent in the broad ligament (Brink et al. 2010). Laterally recumbent, flank laparotomy can also be a feasible treatment option if the mare is not a good candidate for the standing approach (Hendrickson 2012). If during laparoscopy it is observed that SI loops need to be surgically removed, it is recommended to increase the size of the working channel and to perform a SI resection, followed by a rent closure. In case of SI strangulation with dilated and turgid intestinal loops, lack of motility and thickened walls, as was in the case described by us, a standard ventral midline approach is recommended for SI resection, anastomosis (Freeman and Schaeffer 2011) and rent closure. If the rent closure is not possible during surgery, we recommend its closure later on by laparoscopy. This method was previously used to repair a SI mesenteric rent in a mare post-foaling (Sutter and Hardy 2004).

This case study shows that in mares with a history of prolonged labour or dystocia, followed by mild to severe and/or recurrent colic signs, SI herniation through the broad ligament should also be included in the differential diagnosis list. Flank laparoscopy should be performed especially in case of mild recurrent colic to identify the cause of strangulation and to correct the defect. To prevent SI strangulation through the broad ligament, we recommend transrectal palpation of the urogenital tract (including the broad ligament), after both normal foaling and foaling with dystocia and/or other complications. If a defect is identified in the broad ligament, we recommend flank laparoscopy for its correction. As highlighted in the previous care reported in a nonpregnant mare, even if a defect is developed during pregnancy or parturition without inducing SI strangulation, strangulation can occur later (Steward et al. 2018).

\section{Disclosures}

All authors have no conflict of interest to disclose. All authors have approved the final content of the manuscript. No funding was received for this case from any funding agencies in the public, commercial, or not-for-profit sectors.

\section{Acknowledgement}

The authors would like to thank their colleagues at the Equine Clinic for helping in this case management.

\section{References}

Ayala I, Martos NF, Silvan G, Gutierrez-Panizo C, Clavel JG, Illera JC 2012: Cortisol, adrenocorticotropic hormone, serotonin, adrenaline and noradrenaline serum concentrations in relation to disease and stress in the horse. Res Vet Sci 93: 103-107

Bach LG, Ricketts SW 1974: Paracentesis as an aid to the diagnosis of abdominal disease in the horse. Equine Vet J 6: 116-121

Beccati F, Pepe M, Gialletti R, Cercone M, Bazzica C, Nannarone S 2011: Is there a statistical correlation between ultrasonographic findings and definitive diagnosis in horses with acute abdominal pain? Equine Vet $\mathrm{J} 43$ : 98-105

Becht JL, McIlwraith CW 1980: Jejunal displacement through the mesometrium in a pregnant mare. J Am Vet Med Assoc 177: 436

Brink P, Schumacher J, Schumacher J 2010: Elevating the uterus (uteropexy) of five mares by laparoscopically imbricating the mesometrium. Equine Vet J 42: 675-679

Datt SC, Usenik EA 1975: Intestinal obstruction in the horse. Physical signs and blood chemistry. Cornell Vet 65: $152-172$

Davis JL, Blikslager AT, Catto K, Jones SL 2003: A retrospective analysis of hepatic injury in horses with proximal enteritis (1984-2002). J Vet Intern Med 17: 896-901

Feary DJ, Hassel DM 2006: Enteritis and colitis in horses. Vet Clin North Am Equine Pract 22: 437-479, ix

Freeman DE, Schaeffer DJ 2011: Clinical comparison between a continuous Lembert pattern wrapped in a carboxymethylcellulose and hyaluronate membrane with an interrupted Lembert pattern for one-layer jejunojejunostomy in horses. Equine Vet J 43: 708-713

Ginther OJ 1992: Reproductive Biology of the Mare: Basic and Applied Aspects. Equiservices, Cross Plains, Wisconsin, pp. 6-8 
Ginther OJ 1998: Equine pregnancy: physical interactions between the uterus and conceptus. Proc Am Assoc Equine Pract 44: 73-104

Gomaa N, Koeller G, Schusser GF 2009: Triglycerides, free fatty acids and total bilirubin in horses with left ventral colon impaction. Pferdeheilkunde 25: 137-140

Hanson RR, Albanese R 2015: Small Intestine Colic. In: Sprayberry KA, Robinson NE (Eds): Robinson's Current Therapy in Equine Medicine, Elsevier Inc, pp. 328-329

Hassel DM, Hill AE, Rorabeck RA 2009: Association between hyperglycemia and survival in 228 horses with acute gastrointestinal disease. J Vet Intern Med 23: 1261-1265

Hendrickson DA 2012: A review of equine laparoscopy. ISRN Vet Sci 2012: 492650

Latson KM, Nieto JE, Beldomenico PM, Snyder JR 2005: Evaluation of peritoneal fluid lactate as a marker of intestinal ischaemia in equine colic. Equine Vet J 37: 342-346

Mair TS, Edwards GB 2003: Strangulating obstructions of the small intestine. Equine Veterinary Education 15: 192-199

Monreal L, Angies A, Espada Y, Monasterio J, Monreal M 2000: Hypercoagulation and hypofibrinolysis in horses with colic and DIC. Equine Vet J Suppl 32: 19-25

Rowe EL, White NA 2008: Diagnosis of gastrointestinal disease. In: White NA, Moore N, Mair TS (Eds): The Equine Acute Abdomen. Teton Newmedia, Jackson, pp. 236-287

Santschi EM 2009: Colic and pregnancy. In: White NA, Moore JN, Mair TS (Ed.): The equine acute abdomen. Jackson, Wyoming: Teton NewMedia, pp. 677-686

Stephen JO, Corley KTT, Johnston JK, Pfeiffer D 2004: Factors associated with mortality and morbidity in small intestinal volvulus in horses. Vet Surg 33: 340-348

Steward SK, Bauck AG, Zoll W, Conway JA, Freeman DE 2018: Small intestinal strangulation in a tear in the mesometrium of a nonpregnant mare. Equine Vet Educ 30: 591-593

Stockham SL 1995: Interpretation of equine serum biochemical profile results. Vet Clin North Am Equine Pract 11: $391-414$

Sutter WW, Hardy J 2004: Laparoscopic repair of a small intestinal mesenteric rent in a broodmare. Vet Surg 33: 92-95

Taylor FGR 2002: Additional diagnostic procedures. In: Mair TS, Divers TJ, Ducharme N (Eds): Manual of Gastroenterology, W.B. Saunders, London, pp. 9-39

Tennant B, Wheat JD, Meagher DM 1975: Observations on the causes and incidence of acute intestinal obstruction in the horse. Proc Am Assoc Equine Pract 21: 426-438

van den Boom R, van der Velden MA 2001: Short-and long-term evaluation of surgical treatment of strangulating obstructions of the small intestine in horses: a review of 224 cases. Vet Q 23: 109-115

van der Linden MA, Laffont CM, Sloet van Oldruitenborgh-Oosterbaan MM 2003: Prognosis in equine medical and surgical colic. J Vet Intern Med 17: 343-348

Weiss DJ, Evanson OA 2003: Evaluation of activated neutrophils in the blood of horses with colic. Am J Vet Res 64: $1364-1368$

Welles EG 2000: Clinical interpretation of equine leukograms. In: Feldman BF, Zink1 JG, Jain NC (Eds) Schalm's Veterinary Hematology, Lippincott, Williams and Wilkin, Philadelphia, pp. 405-410

Withers JM, Mair TS 2008: Internal (intra-abdominal) herniation in the horse. Equine Vet Educ 20: 639-646 
Plate III

Crecan C. et al.: Small intestinal ... pp. 331-337

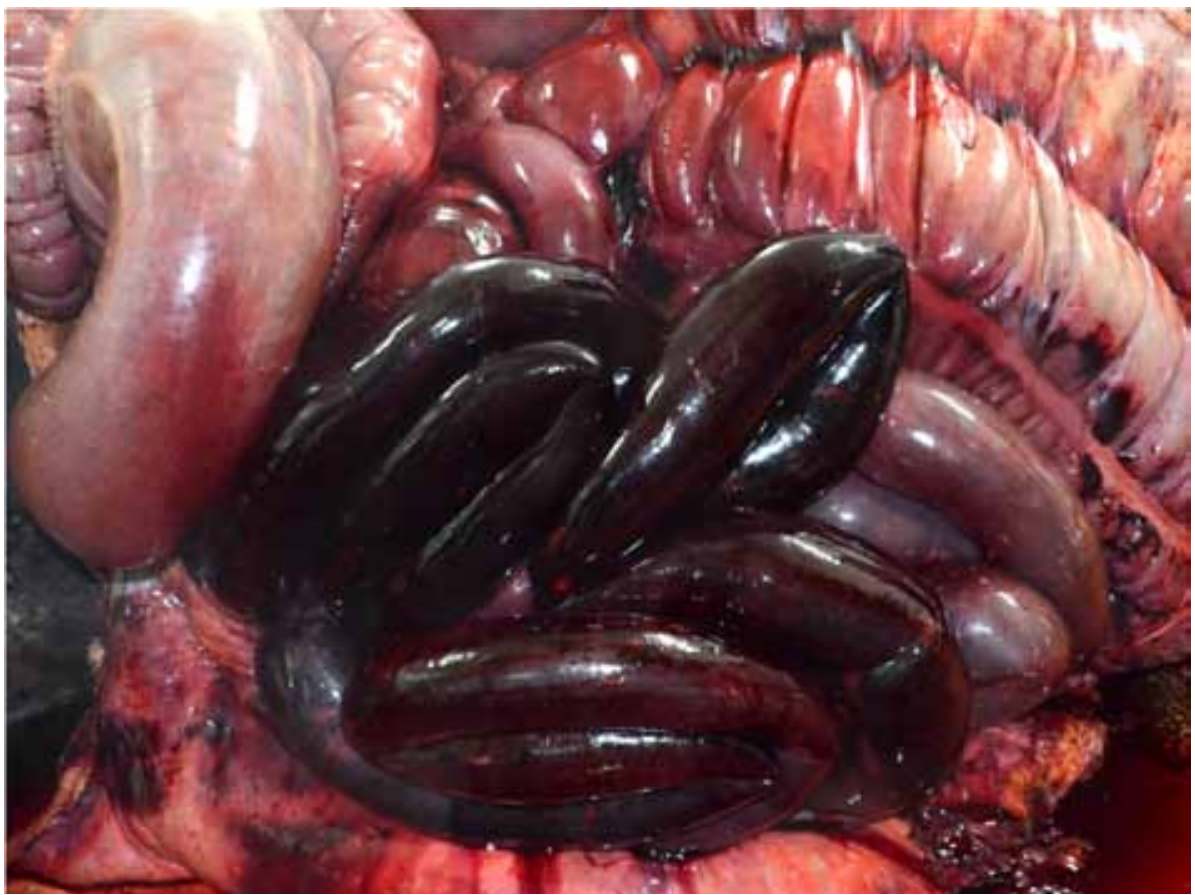

Fig. 1. Strangulated loops of jejunum detected in the caudal quadrant of the abdominal cavity

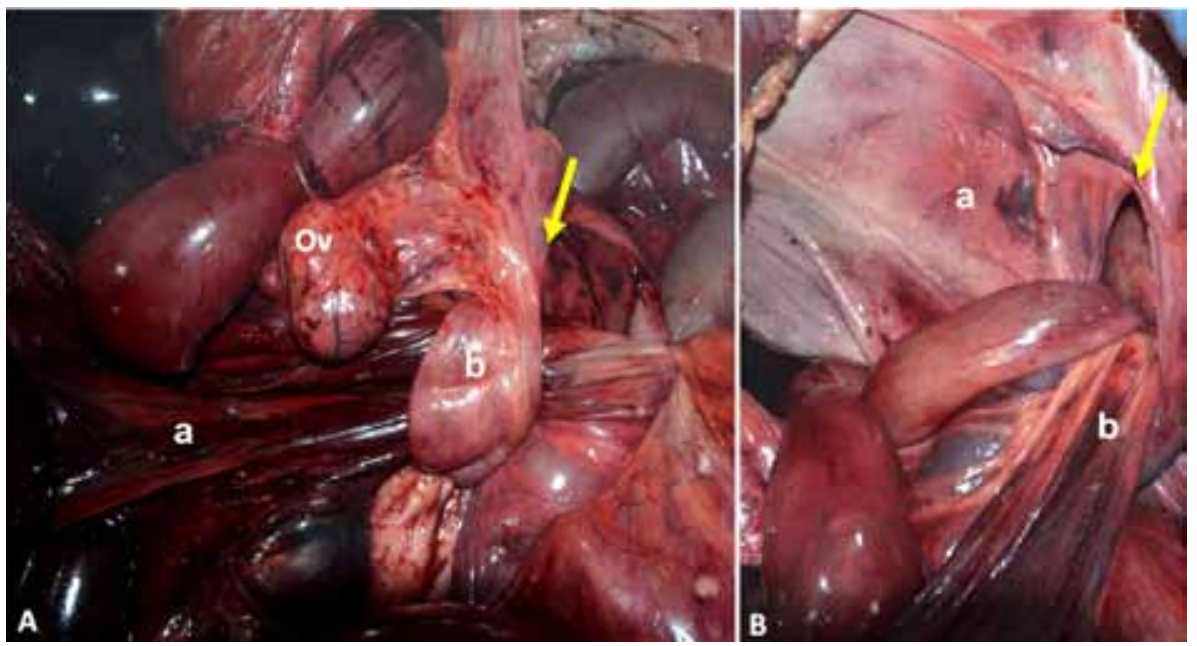

Fig. 2. Internal incarceration of the jejunum (A) through a rent in the left broad ligament of the uterus (B) 2A: the yellow arrow indicates the rent in the mesometrium; Ov - ovary; a - strangulated loops of the jejunum and mesentery; $b$ - uterine horn.

2B: the yellow arrow indicates the rent in the mesometrium; a - petechial haemorrhages and ecchymoses on the mesometrium; $b$ - the demarcation line between the strangulated segment of the intestine and the non-affected intestinal segment 


\section{Plate IV}

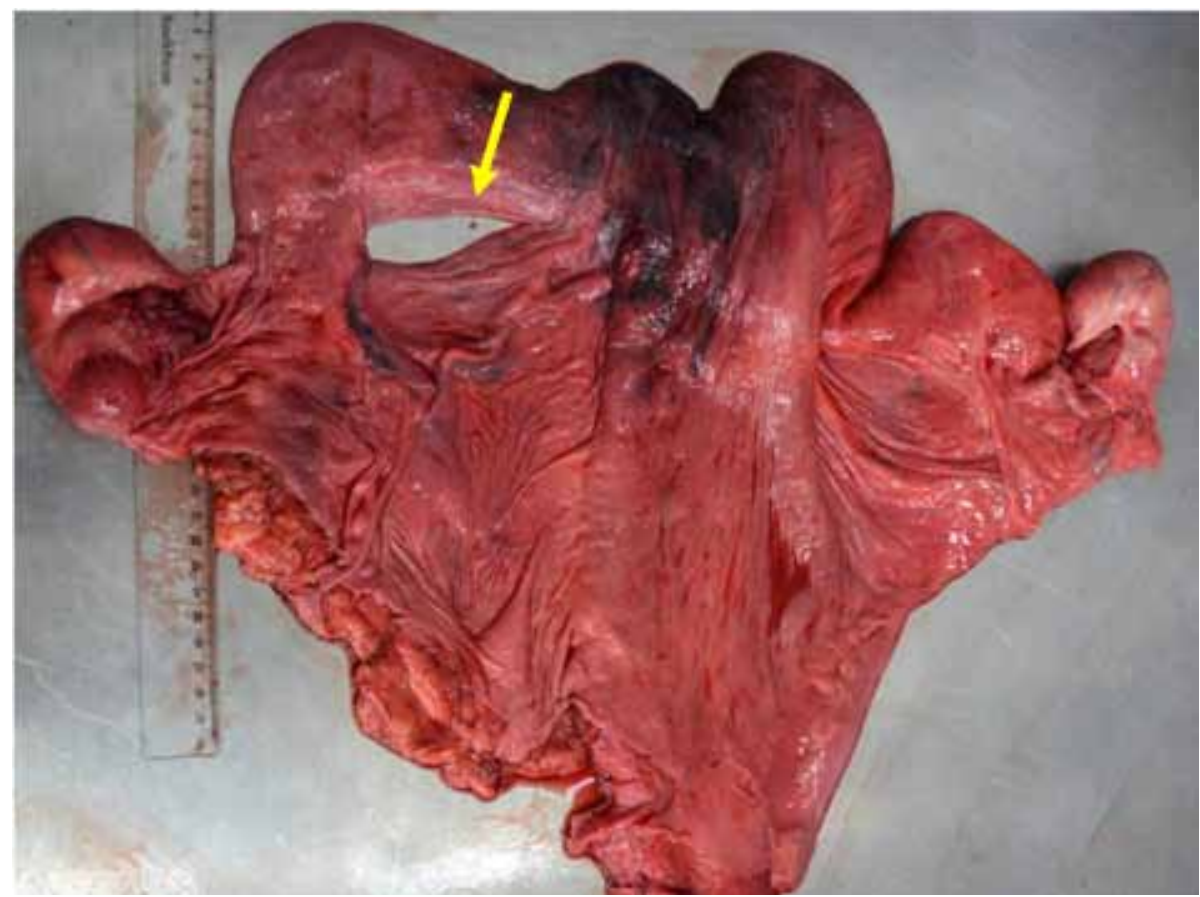

Fig. 3. Dorsal aspect of the uterus and broad ligament

The yellow arrow indicates the rent in the mesometrium, with the small diameter of around $30 \mathrm{~mm}$ and the big diameter of around $50 \mathrm{~mm}$. 